\title{
Discriminating raining from non-raining clouds at mid-latitudes using multispectral satellite data
}

\author{
T. Nauss ${ }^{1}$ and A. A. Kokhanovsky ${ }^{2}$ \\ ${ }^{1}$ Laboratory of Climatology and Remote Sensing, University of Marburg, Germany \\ ${ }^{2}$ Institute of Remote Sensing, University of Bremen, Germany \\ Received: 9 November 2005 - Published in Atmos. Chem. Phys. Discuss.: 20 February 2006 \\ Revised: 21 June 2006 - Accepted: 22 September 2006 - Published: 1 November 2006
}

\begin{abstract}
We propose a new method for the delineation of precipitation using cloud properties derived from optical satellite data. This approach is not only sufficient for the detection of mainly convective precipitation by means of the commonly used connection between infrared cloud top temperature and rainfall probability but enables the detection of stratiform precipitation (e.g., in connection with mid-latitude frontal systems). The scheme presented is based on the concept model, that precipitating clouds must have both a sufficient vertical extent and large enough droplets. Therefore, we have analysed MODIS scenes during the severe European summer floods in 2002 and retrieved functions for the computation of an auto-adaptive threshold value of the effective cloud droplet radius with respect to the corresponding optical thickness which links these cloud properties with rainfall areas on a pixel basis.
\end{abstract}

\section{Introduction}

Water affects all aspects of human life and rainfall is a key process in the hydrological cycle. Detailed knowledge of the spatio-temporal distribution of rainfall is therefore crucial for state of the art hydrological models. Moreover, this information can further improve the reliability of short-term for- and nowcasting applications (e.g. in the context of flood prediction and monitoring). Therefore, many rainfall retrievals based on optical and/or microwave satellite sensors have been developed over the past decades (e.g. Adler and Negri, 1988; Kummerow et al., 2001; Joyce et al., 2004). While optical retrievals mainly focus on the tropics where precipitation is generally linked with deep convective clouds that can be easily identified in the infrared and/or water vapor channels (Levizzani et al., 2001; Levizzani, 2003), mi-

Correspondence to: T. Nauss

(nauss@lcrs.de) crowave sensors aboard polar orbiting satellites (low earth orbit, LEO) can principally be used to delineate stratiform raining cloud regions with homogenous spatial cloud top temperature distributions. On the other hand, these retrievals bear problems concerning the medium temporal resolution of the LEO systems and the high but in general unknown emissivity of land surfaces (Ferraro et al., 1994) that in some extent restricts the application of passive microwave techniques to ocean surfaces. Therefore, optical sensors at a geostationary orbit still play a very important role for the quasi-continuous monitoring of precipitation processes.

In order to improve the quality of optical rainfall retrievals, some authors have suggested to use the effective cloud droplet radius $a_{e f}$ defined as the ratio of the third to the second moment of the cloud droplet spectrum (Hansen and Travis, 1974) and can be retrieved from multi-spectral satellite data. They propose to use values of $a_{e f}$ of around $14 \mu \mathrm{m}$ as a fixed threshold value $(T H V)$ for precipitating clouds (e.g. Rosenfeld and Gutman, 1994; Lensky and Rosenfeld, 1997; Ba, 2000) but these studies have been focused on convective systems and a fixed $T H V$ seems to be not applicable for a reliable delineation between raining and nonraining stratiform clouds that are typical for wide warm or cold frontal bands of mid-latitude frontal systems (Houze, 1993, henceforth referred to as advective/stratiform precipitation). With this in mind, the authors propose a new technique for the identification of precipitating clouds using optical imagery based on an auto-adaptive $T H V$ for $a_{e f}$ with respect to the corresponding cloud optical thickness $\tau$.

\section{A new concept model for the identification of precipi- tating clouds at mid-latitudes}

Due to the very homogenous spatial distribution of cloudtop temperature $T$ for (warm) clouds with values of $T$ differing not significantly between raining and non-raining

Published by Copernicus GmbH on behalf of the European Geosciences Union. 


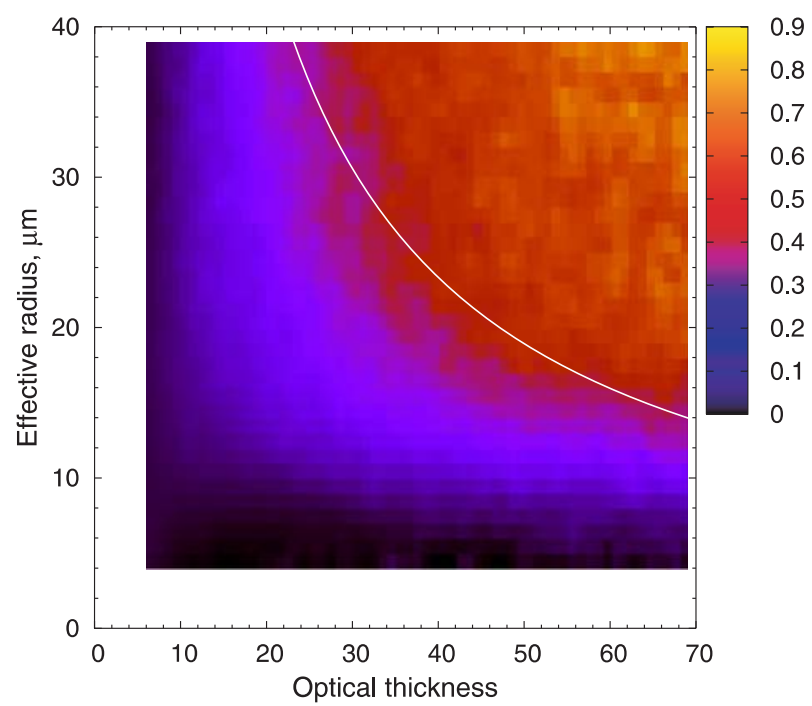

Fig. 1. Rainfall probability of respective combinations between cloud optical thickness and effective droplet radius derived from the comparison of 15 Terra-MODIS scenes between 1 and 15 August 2002 with radar network data from the German weather service over central Europe. The white line shows the delineation function given by Eq. (1)

regions, advective/stratiform precipitation is generally underestimated or even not detected by some of the advanced infrared temperature threshold techniques like the ConvectiveStratiform-Technique CST (Adler and Negri, 1988) or the Enhanced Convective-Stratiform-Technique ECST (Reudenbach, 2003). Therefore, we propose the consideration of the effective cloud droplet radius $a_{e f}$ and the cloud optical thickness $\tau$ instead of the brightness temperature for the detection of precipitation. In contrast to previous studies that focus on convective clouds as mentioned above, no absolute $T H V$ of $a_{e f}$ is used. Instead, our technique is based on an auto-adaptive $T H V$ of $a_{e f}$ with respect to the corresponding value of $\tau$. This idea is based on the concept that rainfall is favoured by both sufficient droplets that can fall easily against updraft wind fields and a large enough vertical cloud extent that allows droplets to grow and prevents them from evaporation below the cloud bottom (which in turn has an influence on the required droplet size; see also Lensky and Rosenfeld, 2003).

In order to prove our concept, satellite-derived cloud properties have been compared to ground-based radar data to derive a function for the auto-adaptive $T H V$ of $a_{e f}$ with respect to the corresponding $\tau$ on a pixel basis. The cloud properties have been retrieved by the Semi-Analyitcal CloUd Retrieval Algorithm (SACURA, Kokhanovsky et al., 2003; Kokhanovsky and Nauss, 2005) using data from the Moderate Resolution Imaging Spectroradiometer (MODIS, http:// modis.gsfc.nasa.gov/) aboard NASA's Terra and Aqua satel- lites with a spatial resolution of $1 \mathrm{~km}^{2}$. SACURA is based on asymptotic solutions and exponential approximations (EA) of the radiative transfer theory valid for weakly absorbing media (Kokhanovsky and Rozanov, 2003, 2004), which are applicable for cloud retrievals up to a wavelength of around $2.2 \mu \mathrm{m}$. For a single scattering albedo $\omega_{0}=1$, the equations coincide with more general asymptotic formulae valid for all values of $\omega_{0}$ (Germogenova, 1963; van de Hulst, 1982; King, 1987) and differ only insignificantly from general equations as $\omega_{0} \rightarrow 1$. However, the EA provides much simpler final expressions, which can be used as a basis for a high-speed cloud retrieval algorithm (Kokhanovsky et al., 2003). SACURA has been validated over sea and land surfaces against the commonly used but computer-time expensive look-up table approaches of the Japanese Space Agency JAXA (Nakajima and Nakajima, 1995; Kawamoto et al., 2001) and the NASA MODIS cloud property product MOD06 (Platnick et al., 2003) showing good agreement for optically thick (e.g., raining) cloud systems (Nauss et al., 2005; Kokhanovsky et al., 2006). The technique used for the computation of auxiliary ground albedo data and the processing of the received MODIS files are described by Nauss and Bendix (2005). Since the final rainfall retrieval should be applicable to geostationary sensors, data from the $0.66 \mu \mathrm{m}$ and $1.6 \mu \mathrm{m}$ MODIS channels similar to those available on Meteosat- 8 SEVIRI are used by the retrievals performed in this study.

In order to derive a rainfall delineation function, the spatial distribution of the SACURA-derived $a_{e f}$ and $\tau$ values has been compared to corresponding ( $+/-7$ min time difference) ground-based radar data provided by the German weather service (DWD) for 15 MODIS scenes over Central Europe taken during the extreme summer floods in August 2002. This time frame has been chosen because it includes not only mainly convective systems but all precipitation processes typical for mid-latitude cyclones. Therefore, one can assume that a function for an auto-adaptive $T H V$ of $a_{e f}$ derived using this dataset is suitable for the description of the precipitation processes at least over Central Europe. Figure 1 shows the resulting rainfall probability for the respective combinations of $\tau$ and $a_{e f}$. The exponential shaped pattern of the probability distribution clearly corroborates our initial hypothesis that rainfall is connected to large enough combinations of the two cloud parameters.

In order to find a discrimination function for raining and non-raining cloud areas that performs best for a large variety of scenes, we iteratively retrieved pairs of the two cloud parameters for each of the 15 MODIS scenes mentioned above that encircle the rainfall area defined by the radar data with a bias better than $+/-5 \%$. Fitting these value combinations results in the following formula for the $T H V$ of the effective radius which is close to the $45 \%$ precipitation probability (see Fig. 1):

$a_{e f}^{*}(\tau)=\frac{A}{\tau}$ 
where $A=920 \mu \mathrm{m}$. The standard error of this approximation is equal to 0.83 . It follows that an assumed fixed $a_{e f}^{*}(\tau)$ of $14 \mu \mathrm{m}$ corresponds to clouds with $\tau \approx 66$. For smaller $\tau$, the $T H V$ for the effective radius is considerably larger. Please note that Eq. (1) is equivalent to a static $T H V$ of the liquid water path of about $0.6 \mathrm{~kg} / \mathrm{m}^{2}$.

\section{An example application of the discrimination func- tion to MODIS data from 30 August 2004}

In order to get a first impression of the performance of the new Rain Area Delineation Scheme (RADS), we applied Eq. (1), which is based on the MODIS scenes from August 2002, to a Terra-MODIS scene from 30 August 2004, 10:38 UTC (Fig. 2). Clouds in the eastern part of the scene shown in Fig. 2a belong to a partly occluded cyclone centered over the North Sea and in the north-western part, convective clouds form due to post-frontal instability. For a better interpretation we computed the rainfall area twice: first using the new RADS and second using routines from the ECST (Reudenbach, 2003) which is similar to the well-known CST (Adler and Negri, 1988) but additionally includes the water vapour channel temperature for a more reliable deep convective/cirrus clouds discrimination (see also Tjemkes et al., 1997). The ECST routines have been used for the identification of convective rain areas since those approximately represent the performance of many present optical rainfall retrievals.

The different rainfall regions identified by the infrared convection scheme (CS, see above) and by RADS are shown in Fig. 2b. Both methods identify the convective cloud regions formed due to potential instability in the north-eastern part of the scene but the comma-shaped trails in the southern part are identified only by RADS. The same applies for most of the post frontal clouds, where only the convective cores are additionally identified by the infrared scheme. Note that every pixel identified by the CS was also identified by RADS.

Figure $2 \mathrm{c}$ shows an overlay of the rainfall area identified by RADS and by the radar network of the German weather service which has been chosen as a "true" reference. The black areas in the most north-western and north-eastern parts indicate the boundaries of the area covered by the radar stations. For the southern border, the northern slope of the Alps has been chosen in order to minimize ground clutter effects in the radar dataset. It can be clearly seen that the radar-based precipitation area is almost entirely identified by the RADS module. Some non-systematic over-/underestimations can be found merely at the edges of the comma-shaped clouds in the southern part. Regarding the precipitating clouds in the post-frontal zone, mainly the cloud cores are identified by the RADS satellite retrieval. This is partly caused by enhanced 3-D radiation effects at the cloud borders that are not accounted for by the cloud property retrieval which assumes a plane-parallel, homogenous cloud layer. Moreover,
Table 1. Results of the standard verification scores applied to the rain-area as identified by RADS and CS on a pixel basis and by RADS but this time allowing a spatial tolerance of $20 \mathrm{~km}$. The scores are based on 937204 pixels of which 204349 have been identified as raining by RADS.

\begin{tabular}{lccc}
\hline & RADS & CS & RADS $(20 \mathrm{~km})$ \\
\hline Bias & 0.85 & 0.25 & 1.00 \\
POD & 0.68 & 0.22 & 0.99 \\
POFD & 0.13 & 0.03 & 0.01 \\
FAR & 0.21 & 0.14 & 0.01 \\
CSI & 0.57 & 0.21 & 0.98 \\
Cloud area & 0.92 & 0.92 & 0.92 \\
\hline
\end{tabular}

the different perspectives between the satellite technique that identifies the cloud-top area responsible for precipitation formation and the radar product that detects the rainfall distribution near ground level could further increase the deviations between the two datasets.

Analogous to the visual impression, standard verification scores for dichotomous datasets are in a good range (see Table 1). The scores are based on the number of pixels that have been identified in the satellite (S) and radar (R) techniques as raining $\left(S_{y}, R_{y}\right)$ or non-raining $\left(S_{n}, R_{n}\right)$. Thereby the bias describes the ratio between $S_{y}$ and $R_{y}$, the probability of detection (POD) the ratio between pixels with $S_{y} R_{y}$ and $R_{y}$, the false alarm ratio (FAR) the ratio between $S_{y} R_{n}$ and $S_{y}$, the probability of false detection (POFD) the ratio between $S_{y} R_{n}$ and $R_{n}$, and the critical success index (CSI) the ratio between $S_{y} R_{y}$ and the sum of $S_{y} R_{y}, S_{n} R_{y}, S_{y} R_{n}$. All scores range from 0 to 1 but the optimum value for the POD and CSI is 1 while it is 0 for the FAR and POFD. For a detailed discussion of the verification scores see Stanski et al. (1989) or the web site of the WWRP/WGNE.

RADS identifies 204349 of 937204 pixels as raining resulting in a bias between the precipitating pixels identified by RADS and the radar product of 0.85 which shows still a tendency for an underdetection of the "true" rainfall area but also an increase by more than factor 3 compared to the bias when only the CS would be used. While the bias includes no information about spatial collocation of the pixels, the POD shows that $68 \%$ of the radar observed raining pixels are also identified by RADS on a $1 \mathrm{~km}^{2}$ basis. Since the POD can be increased by just increasing the satellite rainfall area (i.e. reducing the threshold $a_{e f}^{*}(\tau)$ for raining clouds), corresponding values of the FAR $(21 \%)$ or the POFD (13\%) are of high interest since both measure the fraction of the satellite pixels that have been incorrectly identified as raining but with respect to different denominators $\left(S_{y}\right.$ and $\left.R_{n}\right)$. Since both scores are rather low, the approach seems to have skill at least for the scene presented. This can also be seen in a CSI of 0.57 which encloses all pixels that have been identified as raining by either the radar network or the satellite technique. 

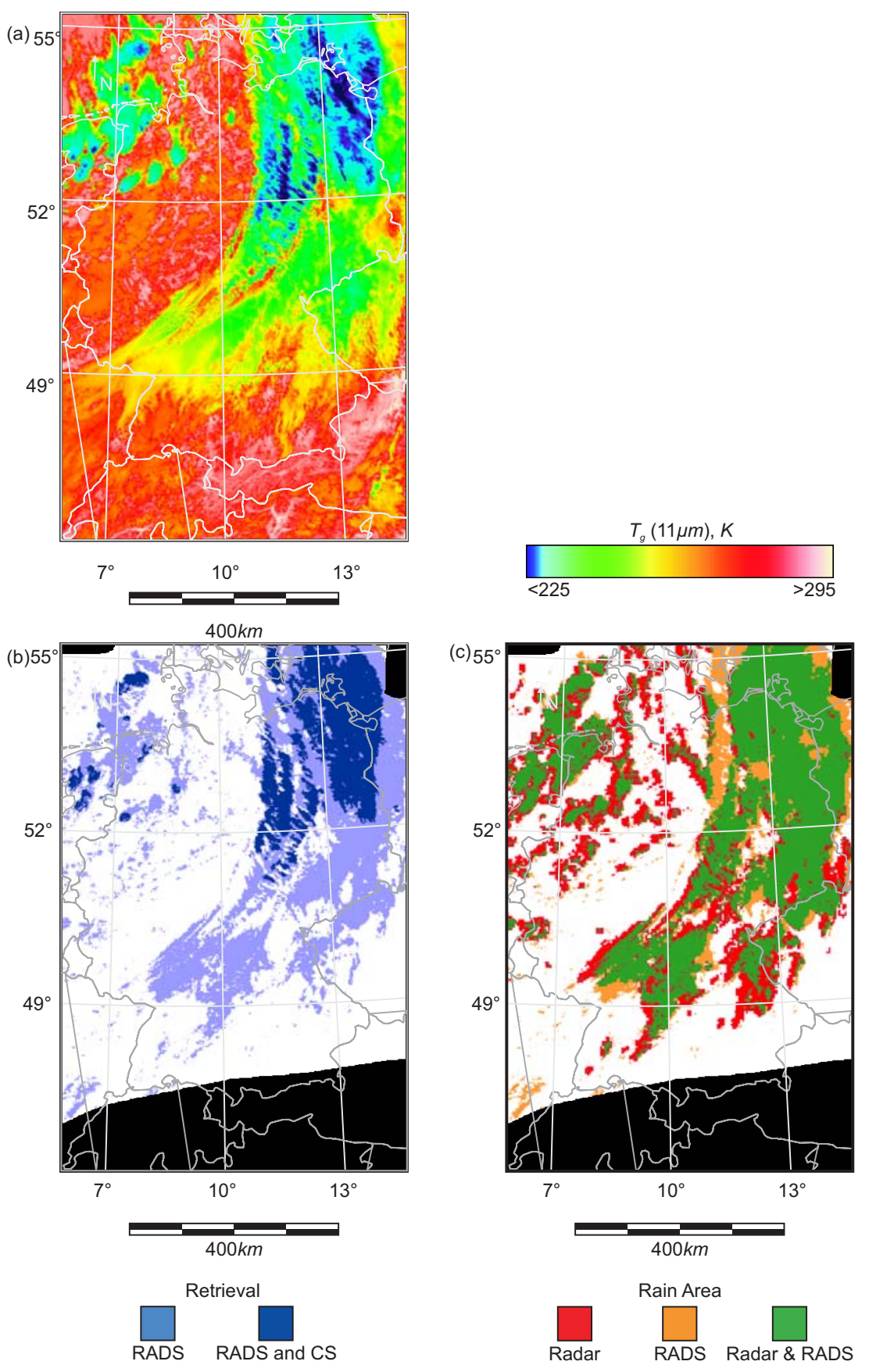

Fig. 2. Comparison between satellite and radar based rainfall areas for the Terra-MODIS scene from 30 August 2004, 10:38 UTC. Panel (a) shows the $11 \mu \mathrm{m}$ brightness temperature, (b) the satellite derived rainfall area identified by the CS and RADS, c) an overlay of precipitating cloud areas identified by RADS and ground-based radar data.

Compared to the CS, this CSI is about factor 2.7 better. Note that this verification was based on a pixel basis of a single scene and no spatio-temporal aggregation (commonly 0.25 to $1^{\circ}$ and $24 \mathrm{~h}$ ) was performed. If we allow a spatial tolerance of $20 \mathrm{~km}$, all scores of RADS differ from their optimum value by not more then $+/-0.02$ (see see Table 1 ) while the scores for the CS would still differ by more than $20 \%$.
With respect to a more general evaluation, an extensive study with over 200 MODIS scenes is currently in process. Preliminary results show a good performance of RADS not only for convective situations like the one presented above but also for weather situations with solely stratiform clouds. 


\section{Conclusions}

A new technique for the identification of precipitating clouds has been presented that delineates raining from non-raining cloud regions by means of the cloud effective droplet radius and the corresponding cloud optical thickness. The retrievals are performed using satellite measurements of the top-ofatmosphere reflectance at wavelengths 0.66 and $1.6 \mu \mathrm{m}$. The delineation is based on the the principle that precipitating clouds must have droplets of sufficient size and a minimum vertical extent to enable sufficient droplet growth and prevent rain droplets from evaporation beneath the cloud base, which in turn has an influence on the required droplet size again. The function derived for the computation of an autoadaptive threshold value of the effective radius with respect to the optical thickness is based on a comparison between the rainfall area detected by ground-based radar and corresponding cloud property distributions retrieved using the computationally fast SACURA technique. The present article shows only first but promising results of the new algorithm and the consideration of the two mentioned cloud properties seems to be important in the context of optical rainfall retrievals at least for the mid-latitudes. The retrieval will be further evaluated and applied to Meteosat-8 SEVIRI data in upcoming studies. Moreover, comprehensive research efforts have just been started in order to develop a new method for the assignment of rainfall rates based on the retrieved cloud properties since the commonly used cloud-top-temperature-to-rainfallintensity relationship seems to be insufficient especially for stratiform cloud areas.

Acknowledgements. This work was supported by the German Federal Ministry for Eduaction and Research (BMBF) in the scope of the GLOWA-Danube project 97 GWK 04 "Rainfall Retrieval", the DFG Project BU 688/8-2 and the Erich-Becker foundation (formerly Frankfurt Airport foundation), Germany.

The authors are grateful to J. Bendix, J. P. Burrows, J. Cermak and C. Reudenbach for valuable discussions, the NASA MODIS team for providing direct broadcast satellite data, and the German weather service (DWD) for providing the radar datasets within the Eumetsat/DWD Advanced Multisensor Precipitation Experiment (AMPE).

Edited by: W. E. Asher

\section{References}

Adler, R. F. and Negri, A. J.: A satellite technique to estimate tropical convective and stratiform rainfall, J. Appl. Meteorol., 27, 30-51, 1988.

Ba, M. B.: Routine rainfall estimation from geostationary satellite, in: The 2000 Eumetsat Meteorological Satellite Data Users' Conference, edited by: Eumetsat, Eumetsat Proceedings, Eumetsat, Eumetsat, Bologna, 2000.
DWD: Weather radar network, available online at http: //www.dwd.de/en/Technik/Datengewinnung/Radarverbund/ Radarbroschuere_en.pdf, 7 November 2005.

Ferraro, R. R., Grody, N. C., and Marks, G. F.: Effects of surface conditions on rain identification using the DMSP-SSM/I, Remote Sens. Rev., 11, 195-210, 1994.

Germogenova, T. A.: Some formulas to solve the transfer equation in the plane layer problem, in: Spectroscopy of Scattering Media, edited by: Stepanov, B. I., Academy of Sciences of BSSR, Minsk, 36-41, 1963.

Hansen, J. E. and Travis, L. D.: Light scattering in planetary atmospheres, Space Sci. Rev., 16, 527-610, 1974.

Houze, R. A.: Cloud Dynamics, vol. 53 of the International Geophysics Series, Academic Press, San Diego, 1993.

Joyce, R. J., Janowiak, J. E., Arking, P. A., and Xie, P.: CMORPH: a method that produces global precipitation estimates from passive microwave and infared data at high spatial and temporal resolution, J. Hydrometeorol., 5, 487-503, 2004.

Kawamoto, K., Nakajima, T., and Nakajima, T. Y.: A global determination of cloud microphysics with AVHRR remote sensing, J. Climate, 14, 2054-2068, 2001.

King, M. D.: Determination of the scaled optical thickness of clouds from reflected solar radiation measurements, J. Atmos. Sci., 44, 1734-1751, 1987.

Kokhanovsky, A. A. and Rozanov, V. V.: The reflection function of optically thick weakly absorbing turbid layers: a simple approximation, J. Quant. Spectr. Radiat. Trans., 77, 165-175, 2003.

Kokhanovsky, A. A. and Rozanov, V. V.: The physical parameterization of the top-of-atmosphere reflection function for a cloudy atmosphere -underlying surface system: the oxygen A-band case study, J. Quant. Spectr. Radiat. Trans., 85, 35-55, 2004.

Kokhanovsky, A. A. and Nauss, T.: Satellite-based retrieval of ice cloud properties using a semi-analytical algorithm, J. Geophys. Res.-Atmos., 110/D19, D19206, doi:10.1029/2004JD005744, 2005.

Kokhanovsky, A. A., Rozanov, V. V., Zege, E. P., Bovensmann, H., and Burrows, J. P.: A semi-analytical cloud retrieval algorithm using backscattered radiation in 0.4-2.4 micrometers spectral range, J. Geophys. Res., 108(D1), 4008, doi:10.1029/2001JD001543, 2003.

Kokhanovsky, A. A., Rozanov, V. V., Nauss, T., Reudenbach, C., Daniel, J. S., Miller, H. L., and Burrows, J. P.: The semianalytical cloud retrieval algorithm for SCIAMACHY. I. The validation, Atmos. Chem. Phys., 6, 1905-1911, 2006, http://www.atmos-chem-phys.net/6/1905/2006/.

Kummerow, C. D., Hong, Y., Olson, W. S., Yang, S., Adler, R. F., McCollum, J., Ferraro, R., Petty, G., Shin, D. B., and Wilheit, T. T.: The evolution of the Goddard Profiling Algorithm (GPROF) for rainfall estimation from passive microwave sensors, J. Appl. Meteorol., 40, 1801-1820, 2001.

Lensky, I. M. and Rosenfeld, D.: Estimation of Precipitation Area and Rain Intensity Based on the Microphysical Properties Retrieved from NOAA AVHRR Data, J. Appl. Meteorol., 36, 234242, 1997.

Lensky, I. M. and Rosenfeld, D.: Satellite-based insights into precipitation formation processes in continental and maritime convective clouds at nighttime, J. Appl. Meteorol., 42, 1227-1233, 2003.

Levizzani, V.: Satellite rainfall estimations: new perspectives for 
meteorology and climate from the EURAINSAT project., Ann. Geophys., 46, 363-372, 2003, http://www.ann-geophys.net/46/363/2003/.

Levizzani, V., Schmetz, J., Lutz, H. J., Kerkmann, J., Alberoni, P. P., and Cervino, M.: Precipitation estimations from geostationary orbit and prospects for Meteosat Second Generation, Meteorological Applications, 8, 23-41, 2001.

Nakajima, T. Y. and Nakajima, T.: Wide-area determination of cloud microphysical properties from NOAA AVHRR measurements for FIRE and ASTEX regions, J. Atmos. Sci., 52, 40434059, 1995.

Nauss, T. and Bendix, J.: An operational MODIS processing scheme for PC dedicated to direct broadcasting applications in meteorology and earth sciences, Computers and Geosciences, 31(6), 804-808, 2005.

Nauss, T., Kokhanovsky, A. A., Nakajima, T. Y., Reudenbach, C., and Bendix, J.: The intercomparison of selected cloud retrieval algorithms, Atmos. Res., 78, 46-78, 2005.

Platnick, S., King, M. D., Ackerman, S. A., Menzel, W. P., Baum, B. A., Riédi, J. C., and Frey, R. A.: The MODIS cloud products: Algorithms and examples from Terra, IEEE Transactions on Geoscience and Remote Sensing, 41, 459-473, 2003.
Reudenbach, C.: Konvektive Sommerniederschlge in Mitteleuropa. Eine Kombination aus Satellitenfernerkundung und numerischer Modellierung zur automatischen Erfassung mesoskaliger Niederschlagsfelder, Bonner Geographische Abhandlungen, 109, 152 pp., 2003.

Rosenfeld, D. and Gutman, G.: Retrieving microphysical properties near the tops of potential rain clouds by multispectral analysis of AVHRR data, Atmos. Res., 34, 259-283, 1994.

Stanski, H. R., Wilson, L., and Burrows, W.: Survey of common verification methods in meteorology., World Weather Watch Technical Report No.8 8, WMO, Geneva, WMO/TD No. 358, 114 p., 1989.

Tjemkes, S. A., van de Berg, L., and Schmetz, J.: Warm water vapour pixels over high clouds as observed by Meteosat, Beitraege zur Physik der Atmosphäre, 70, 15-21, 1997.

van de Hulst, H. C.: Ligth scattering by small particles, Dover Publications, 1982.

World Weather Research Program/Working Group on Numerical Experimentation Joint Working Group on Verification (WWRP/WGNE): Forecast Verification - Issues, Methods and FAQ, available online at http://www.bom.gov.au/bmrc/wefor/ staff/eee/verif/verif_web_page.html, 7 November 2005. 